\title{
Challenges in Screening, Diagnosis and Management of Colorectal Cancers in Covid-19 Era
}

\author{
Sumit Kumar ${ }^{3}$, Vishal Kaundal ${ }^{2}$, Vandana Singh Kushwaha ${ }^{5}$, Shalini \\ Verma $^{1 *}$, Muninder Negi ${ }^{1}$ and Nitin Gupta ${ }^{4}$ \\ ${ }^{1}$ Radiation Oncology Department, Dr RPGMC, Tanda, Himachal Pradesh, India \\ ${ }^{2}$ Surgery Department, Dr RPGMC, Tanda, Himachal Pradesh, India \\ ${ }^{3}$ Radiation Department, AIIMS, New Delhi, India \\ ${ }^{4}$ Nuclear Medicine Department, Dr RPGMC, Tanda, Himachal Pradesh, India \\ ${ }^{5}$ Radiation Oncology, Vydehi Institute of Medical Sciences and Research Centre, \\ Bengaluru, Karnataka, India \\ *Corresponding Author: Shalini Verma, Radiation Oncology Department, \\ Dr RPGMC, Tanda, Himachal Pradesh, India.
}

\author{
Received: October 23, 2020 \\ Published: October 31, 2020 \\ (C) All rights are reserved by Shalini Verma., \\ et al.
}

\begin{abstract}
The coronavirus pandemic has become global health emergency. This pandemic stage has brought great challenges to the diagnosis and management of Colorectal cancer (CRC). Surgery being the cornerstone of treatment is difficult to perform at this stage when there is so much burden on the limited hospital resources and social distancing is the only hope of staying protected from such contagious virus. Moreover cancer patients are highly susceptible to Covid-19 infection and treating cancer patients like before is associated with devastating complication with very poor outcome. At this stage healthcare providers should not emphasize only on therapeutics strategy but also on prevention from Covid-19. In this paper we have focused on the challenges pertaining to the screening, diagnosis and management of CRC and the best efforts that can to made to mitigate risks with the available resources.

Keywords: Covid-19; Colorectal Cancer (CRC); Coronavirus Disease
\end{abstract}

\section{Introduction}

Coronavirus disease (Covid-19) has become global health emergency $[1,2]$. This pandemic has brought great challenges to the diagnosis and management of Colorectal cancer (CRC). CRC is the disease of old age, and Covid-19 is known for causing higher deaths in older age groups (China: $8 \%$ and 14.8\%; Italy: 12/8\% and $20.2 \%$ for the patients over the age of 70 and 80 years, respectively [3]. CRC is a wasting disease in itself, treatment of which results in further immunosuppression and thereby higher susceptibility to Covid-19 infection. The gastrointestinal and urinary tract are considered as the potential routes of transmission where SARS-Cov-2 has been often detected, hence CRC deserves special attention and should be diagnosed and treated properly [4].

Here, we discuss the useful strategies for diagnosis and management plan of CRC patients during the COVID-19 outbreak based on previous guidelines, the current working status and our experiences, to provide a reference for clinical practitioners.

Why is CRC the disease of concern in Covid-19 pandemic

Cancer patients have high risk of contracting Covid-19 and dying from it $[3,5]$. The death rate of $25 \%$ was found in one study on cancer patients in Wuhan [6].

CRC is an old age disease mostly occurring in more patients of than 60 years with/without comorbidities, which have been identified as risk factors for covid-19 severe course by themselves.

\section{Challenges in screening and diagnosis of CRC}

CRC is a preventable disease by screening, but owing to the fear of virus transmission many countries have suspended CRC screening programmes (faecal occult blood testing and/or endoscopy 
based) [7]. This can result in devastating consequences especially in high risk patients. Also it has been found that patients testing positive on faecal immunochemical tests were found to have advanced stage CRC when colonoscopy was delayed by more than 6 months [8].

It is well known that virus exists in the gastrointestinal tract and faeces besides in respiratory tract [9], the physical examination including digital rectal examination (DRE) should be done cautiously by taking all the protective measures. One small study found that RNA was found for prolonged duration in rectal swab even after clearance from respiratory tract raising the concern of fecal-oral transmission of SARS-CoV-2 [10].

The endoscopy procedure is associated with high very risk of infection to the endoscopist via conjunctival contact, airborne contact or faecal-oral transmission [11,12]. The type of disinfection carried out earlier may not lead to eradication/inactivation of this novel coronavirus, thereby, increasing the risk to the doctor and medical staff. Hence, in the suspected/confirmed cases of SARS-CoV-2 infection, if at al the endoscopic procedure is required, should be done in properly ventilated isolated rooms and after the procedure the instruments and the room should be properly sterilized by using vaporized hydrogen peroxide [13].

One should remain vigilant and should not get confused with the common symptoms of CRC and SARS-CoV-2 infection. The patients infected with coronavirus also sometimes presents with the symptoms like diarrhoea, nausea, vomiting and abdominal pain/ discomfort and later on with respiratory symptoms [14].

Also, CRC patients with lung metastasis have features like cough, fever with pulmonary shadow on Chest-Xray. These cases should be further confirmed with further testing like viral nucleic acid, CT/Xray chest (pneumonia like picture or patchy or ground glass opacity in Covid-19 infection) and tumour markers [15]. Another confusing symptom is fever occurring as a result of intestinal obstruction or chemotherapy induced neutropenia in CRC.

\section{What possible can be done}

Mailed FIT outreach programme should be initiated. FIT is an inexpensive test with sensitivity of $79 \%$, specificity of $94 \%$, and overall diagnostic accuracy of $95 \%$ for CRC and can be done easily at home, colonoscopies should be performed only in those testing positive $[16,17]$.
Further, for patients awaiting diagnostic tests or having worrying symptoms should also be offered these non-invasive tests. Mowat., et al. demonstrated $>40 \%$ reduction in invasive tests with the use of non-invasive tests [18].

\section{Challenges in management of CRC}

Surgery is the only curative modality in CRC. The old aged, comorbid and immunosuppressed patients have to undergo prolonged surgical procedures requiring high dependency on intensive care units and prolonged hospitalisation. Moreover, surgical intervention puts the whole team at very high the risk of Covid-19 exposure. Further, it is well known that medical staff is already struggling with the shortage of masks, gloves and personal protective equipment. Moreover, the requirement of post-surgery hospitalisation for minimum of 2-3 days at the time of limited hospital resources is challenging [19].

\section{What possible can be done}

Limiting the surgeries to emergencies only while postponing the others. As every hospital visit increases the risk of virus exposure and transmission. Many studies have suggested that delaying of surgery for 8-12 weeks does not have negative impact on survival outcome [20,21].

Further, another study on 4685 patients found no association between treatment delay and reduced overall survival in patients with CRC [21].

\section{In rectal carcinoma}

For T1 disease- Local excision through endoscopic or transanal route should be considered over total mesorectal excision.

\section{For locally advanced rectal cancer}

Both preoperative Short course radiotherapy (SCPRT) and long course chemoradiotherapy (LCCRT) are standard of treatment. In COVID-19 Pandemic SCPRT (25GY/5\#/1week) followed by either immediate or surgery after 8-10 weeks can be considered [22].

Another strategy as in Rapido trial where SCPRT followed by Capox (6 cycles) or FOLFOX ( 9 cycles) and subsequent surgery can be considered [23].

Patients with complete response to neoadjuvant treatment can be kept on wait and watch protocol. 
For patients presenting with bowel obstruction and stage IV disease- Stent placement should be considered as an alternative to surgery.

The use of adjuvant chemotherapy can be limited, many studies have found no or limited benefit [24].

\section{Colon cancer}

Liu., et al. from China reported 47 locally advanced colon cancer patients (T3/T4a-b) treated by CapOX (oxaliplatin plus capecitabine) regimen, the authors concluded that NACT with CapOX was an effective and safe option for these patients [25].

In high risk stage II and early stage low-risk stage III patients should be given 3 months of adjuvant Capox instead of 6 months owing to the evidence revealing noninferiority results with 3 months of adjuvant chemotherapy in IDEA Meta-analysis [26].

For the patients in good general condition presenting with bowel obstruction may be considered for endoscopic colonic stenting procedure using self-expanding metallic stents (SEMS) [27]. Continuing or starting NACT may further shrink the size of tumors even to achieve downstaging.

Patients having refractory bowel obstruction, perforation and hemorrhage failing the alternative measures should be considered for emergency operation after taking proper preventive measures as shown in figure 1.

\begin{tabular}{|c|c|c|}
\hline & Treatment options & Suggested Alternatives \\
\hline Adjuvant chemotherapy in colon cancer & & \\
\hline High risk Stage 2 & CAPOX X 3 months & Observation/Capox X 3 months \\
\hline $\begin{array}{l}\text { MSI-H stage pT } 4 \text { only } \\
\text { MSS }\end{array}$ & $\begin{array}{l}\text { Single agent Capecitabine/FOLFOX/ } \\
\text { Capox }\end{array}$ & Oral capecitabine X 6 months/3 months Capox \\
\hline Low Risk Stage 3 & $\begin{array}{l}\text { CAPOX X } 3 \text { months } \\
\text { FOLFOX X } 6 \text { months }\end{array}$ & $\begin{array}{l}\text { Capox X } 3 \text { months } \\
\text { Oral Capecitabine X } 6 \text { months }\end{array}$ \\
\hline High Risk Stage 3 & $\begin{array}{l}\text { CAPOX X } 6 \text { months } \\
\text { FOLFOX X } 6 \text { months }\end{array}$ & $\begin{array}{c}\text { CAPOX X } 6 \text { months } \\
\text { Capecitabine X } 2 \text { f/b CAPOX X } 6 \text { cycles }\end{array}$ \\
\hline Elderly Patients & Single agent Capecitabine & Oral Capecitabine \\
\hline $\begin{array}{l}\text { Adjuvant Therapy in Rectal Cancer } \\
\text { Good responders (pCR,yP T1-2) }\end{array}$ & $\begin{array}{c}\text { FOLFOX } \\
\text { CAPOX } \\
\text { Capecitabin }\end{array}$ & Oral Capecitabine \\
\hline Poor Responders & $\begin{array}{l}\text { CAPOX } \\
\text { FOLPOX }\end{array}$ & $\begin{array}{l}\text { CAPOX X } 3 \text { months } \\
\text { Capecitabine X } 6 \text { months }\end{array}$ \\
\hline $\begin{array}{l}\text { Metastatic Colorectal Cancer } \\
\text { (Treatment naive) }\end{array}$ & $\begin{array}{l}\text { CAPOX } \\
\text { FOLFOX } \\
\text { FOLFIRI }\end{array}$ & $\begin{array}{c}\text { CAPOX } \\
\text { Modified XELIRI } \\
\text { TEGAFOX }\end{array}$ \\
\hline Post Oxaliplatin based chemotherapy & FOLFIRI & $\begin{array}{c}\text { Modified XELIRI } \\
\text { TEGAFIRI }\end{array}$ \\
\hline
\end{tabular}

Table 1: Summary of alternatives that can be used in the management of colorectal cancer in this pandemic. 


\begin{tabular}{|c|c|c|c|c|}
\hline $\begin{array}{l}\text { Treatment } \\
\text { modality }\end{array}$ & $\begin{array}{c}\text { Treatment to be com- } \\
\text { menced } \\
\text { If possible }\end{array}$ & $\begin{array}{c}\text { Treatment not to be } \\
\text { commenced without } \\
\text { justification }\end{array}$ & $\begin{array}{l}\text { Treatment not to be } \\
\text { stopped } \\
\text { without justification }\end{array}$ & $\begin{array}{l}\text { Treatment can be stopped de- } \\
\text { layed after consideration }\end{array}$ \\
\hline Adjuvant & $\begin{array}{l}\text { Rectal Cancer, NACT } \\
\text {-5FU/Oxaliplatin stage } \\
\text { III, 4-8 weeks post-op }\end{array}$ & $\begin{array}{l}\text { Oxaliplatin for stage } \\
\text { IIICRC CAPOX }\end{array}$ & $\begin{array}{l}\text { Adjuvant 5FU/Cape for } \\
\text { stage III (month 1-3) }\end{array}$ & $\begin{array}{c}\text { Oxaliplatin in adjuvant } \\
\text { Adjuvant after } 3 \text { months } \\
\text { Routine Follow-up labs and scans } \\
\text { Routine Colonoscopy }\end{array}$ \\
\hline Metastatic & Frontline Met CRC & - & $\begin{array}{l}\text { Induction Chemo for met } \\
\text { Resection }\end{array}$ & $\begin{array}{l}\text { Maintenance therapy } \\
\text { Palliative chemo } \\
\text { Follow up scans if stable }\end{array}$ \\
\hline Surgery & $\begin{array}{l}\text { Primary Resection } \\
\text { Obstruction, severe } \\
\text { bleeding }\end{array}$ & $\begin{array}{l}\text { Elective Liver or other } \\
\text { met resections }\end{array}$ & - & $\begin{array}{l}\text { Elective Liver or other } \\
\text { met resections } \\
\text { Rectal Resections after } \\
\text { NACT response }\end{array}$ \\
\hline Radiation & Palliative RT & Rectal Chemo/ RT & Rectal Chemo/RT & $\begin{array}{c}\text { Post op RT } \\
\text { Palliative RT if pain } \\
\text { Controlled }\end{array}$ \\
\hline
\end{tabular}

Table 2: Treatment modification strategies for CRC in ovid-19 era.

CRC: Colorectal Cancer, RT: Radiotherapy.

Drop off of i.v bolus 5FU in FOLFOX/FOLFIRI.

Change of i.v 5FU to oral Capecitabine.

Skipping of the maintenance adjuvant cycles for a month or two.

Changing the i.v portion of the regimen to oral ones.

Managing orals with telemedicine visits.

Spreading out of mediport flushes to 6-8 weeks

Considering short course radiotherapy wherever possible.

Considering tumour cell DNA for adjuvant treatment decision.

Delaying of surgeries by 2-3 months when possible.

Table 3: Changes in nutshell.

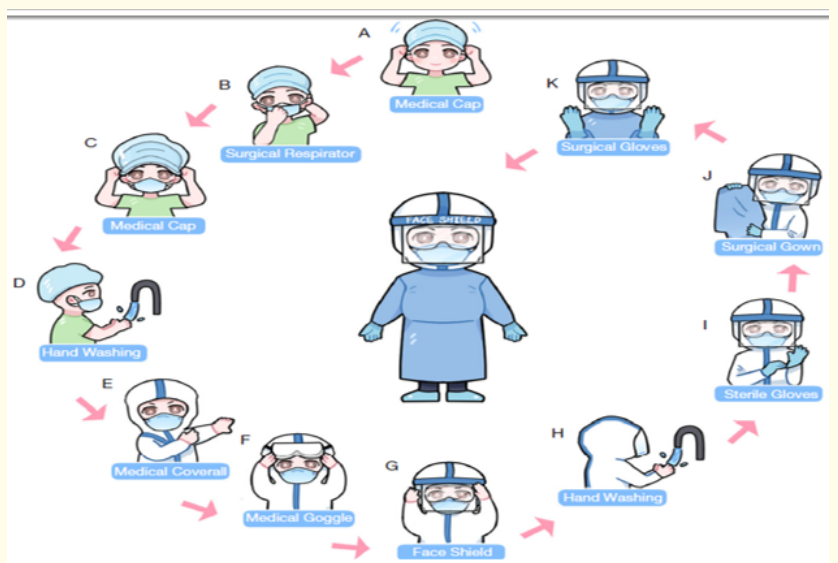

Figure 1: Personal protective measures to be taken by the medical staff during surgery for suspected/confirmed cases.

\section{Conclusion}

It is important to recognize and find out the significant modifications that can be made in current standard guidelines that would unlikely result in any major significant negative impact on patient outcome. Further, reducing exposure time is an essential step in preventing spread of SARS-Cov infection. Therefore, treatment options like taking oral chemotherapy instead of intravenous chemotherapy, by extending the interval of neoadjuvant therapy and choosing nearest hospital for necessary treatment would result in decreasing overburden on existing healthcare resources without compromising the long term outcome in cancer patients.

Apart from these recommendation's there is need to focus on general principles like social-distancing in outpatient departments and increasing the use of telemedicine to decrease hospital visits.

\section{Bibliography}

1. Guan WJ., et al. "Clinical Characteristics of Coronovirus Disease 2019 in China". The New England Journal of Medicine 382 (2020): 1708-1720.

2. Guo YR., et al. "The Origin, transmission and clinical therapies on coronavirus disease 2019 (COVID-19) outbreak -an update on the status". Military Medical Research 7.1 (2020): 11.

3. Onder G., et al. "Case-fatality rate and characteristics of patients dying in relation to COVID-19 in Italy". JAMA 323.18 (2020): 1775-1776. 
4. Wang L., et al. "Chinese expert consensus on the perinatal and neonatal management for the prevention and control of the 2019 novel coronavirus infection (First edition)". Annals of Translational Medicine's 8 (2020): 47.

5. Liang W., et al. "Cancerpatients in SARS-Cov-2 infection: A Nationwide analysis in China". Lancet Oncology 21 (2020): 335337.

6. Yu J., et al. "SARS-Cov-2 transmission in patients with cancer at a tertiary care hospital in Wuhan, China". JAMA Oncology 6.7 (2020): 1108-1110.

7. Saftoiu A., et al. "Role of gastriontesinal endoscopy in the screening of digestive tract cancers in Europe: European Society of Gastrointestinal Endoscopy (ESGE) Position Statement". Endoscopy 52 (2020): 293-304.

8. Lee Y., et al. "Time to Colonoscopy and risk of Colorectal Cancer in patients with positive results from fecal immunochemical tests". Clinical Gastroenterology and Hepatology 17.7 (2019): 1332-1340.

9. Zhang H., et al. "The digestive system is a potential route of 2019-n Cov infection: a bioinformatics analysis based on single-cell transcriptomes". bioRxiv (2020).

10. Xu Y., et al. "Characteristics of pediatrics SARS-Cov-2 infection and potential evidence for persistant fecal viral shedding". $\mathrm{Na}$ ture Medicine 26 (2020): 502-505.

11. Huang C., et al. "Clinical features of patients infected with 2019 novel coronavirus in Wuhan, China". Lancet 395 (2020): 497506.

12. Gu J and Han J. "COVID-19: Gastrointestinal manifestations and potential fecal-oral transmission". Gastroenterology 158.6 (2020): 1518-1519.

13. Shi Q., et al. "Diagnosis and treatment of emergency digestive endoscopy in Zhongshan hospital of Fudan university during the outbreak of COVID-19". Chinese Journal of Digestive Endoscopy 115.6 (2020): 805-808.

14. Wang D., et al. "Clinical characteristics of 138 hospitalized pateints with 2019 novel coronavirus-infected pneumonia in Wuhan, China". JAMA 323.11 (2020): 1061-1069.

15. Zhang J., et al. "Clinical characteristics of 140 patients infected with SARS-Cov-2 in Wuhan, China”. Allergy 75.7 (2020): 17301741.
16. Lee JK., et al. "Accuracy of fecal immunohistochemical tests for colorectal cancer: systemic review and meta-analysis". Annuals of Internal Medicine 160.3 (2014): 171.

17. Rabeneck L., et al. "International perspective on the burden of colorectal cancer and public health effects". Gastroenterology 158.2 (2020): 447-52.

18. Mowat C., et al. "Fecal haemoglobin and fecal calprotectin as indicators of bowel disease in patients presenting to primary care with bowel symptom". Gut 65 (2016): 1463-1469.

19. Thiele RH., et al. "Standardization of Care Impact of Enhanced Recovery Protocol on Length of Stay, Complications, and Direct Costs after Colorectal Surgery". Journal of the American College of Surgeons 220 (2015): 430-443.

20. Bagaria SP., et al. "Delay to colectomy and survival for pateints diagnosed with colon cancer". Journal of Investigation Surgery 32 (2019): 350-357.

21. Hangard Hansen C., et al. "The effect of time from diagnosis to surgery on oncological outcomes in pateints undergoing surgery for colon cancer: a systematic review". European Journal of Surgical Oncology 44 (2018): 1479-1485.

22. Erlandsson J., et al. "Optimal fractionation of preoperative radiotherapy and timing to surgery for rectal cancer (Stockholm III): a multicentre, randomised, non blinded, phase 3, non inferiority trial". Lancet Oncology 18 (2017): 336-346.

23. Van der Valk MJM., et al. "Compliance and tolerability of shortcourse radiotherapy followed by preopertaive chemotherapy and surgery high-risk rectal cancer-results of the international randomised RAPIDO-trial". Radiotherapy Oncology 147 (2020): 75-83.

24. Carvalho C and Glynne-Jones R. "Challenges behing proving efficacy of adjuvant chemotherapy after preopertaive chemoradiation for rectal cancer". Lancet Oncology 18 (2017): 354363.

25. Liu F., et al. "CapOX as neoadjuvant chemotherapy for locally advanced operable colon cancer patients: a prospective single-arm phase II trial". Chinese Journal of Cancer Research 28 (2016): 589-597.

26. Timothy Iveson., et al. "Prospective pooled analysis of four randomised trials investigating duration of adjuvant oxaliplatin- based therapy ( 3 vs 6 months) for patients with highrisk stage II colorectal cancer". Journal of Clinical Oncology 37 (2019): 3501. 
27. Chen YH., et al. "Treatment strategy for gastrointestinal tumour under the outbreak of novel coronavirus pneumonia in China". Zhonghua Wei Chang Wai Ke Za Zhi 23 (2020): I-IV.

\section{Assets from publication with us}

- Prompt Acknowledgement after receiving the article

- Thorough Double blinded peer review

- Rapid Publication

- Issue of Publication Certificate

- High visibility of your Published work

Website: www.actascientific.com/

Submit Article: www.actascientific.com/submission.php

Email us: editor@actascientific.com

Contact us: +919182824667 